\title{
Umbilical cord blood-derived non- hematopoietic stem cells retrieved and expanded on bone marrow-derived extracellular matrix display pluripotent characteristics
}

Junjie Wu ${ }^{1,2+}$, Yun Sun ${ }^{1,3+}$, Travis J. Block ${ }^{1,4}$, Milos Marinkovic ${ }^{1,4}$, Zhi-Liang Zhang ${ }^{1,5}$, Richard Chen ${ }^{1}$, Yixia Yin ${ }^{1,6}$, Juquan Song ${ }^{7}$, David D. Dean ${ }^{1,4}$, Zhongding Lu ${ }^{1 *}$ and Xiao-Dong Chen ${ }^{1,8^{*}}$

\begin{abstract}
Background: Umbilical cord blood (UCB) not only contains hematopoietic stem cells (HSCs), but also nonhematopoietic stem cells (NHSCs) that are able to differentiate into a number of distinct cell types. Based on studies published to date, the frequency of NHSCs in UCB is believed to be very low. However, the isolation of these cells is primarily based on their adhesion to tissue culture plastic surfaces.

Methods and results: In the current study, we demonstrate that this approach overlooks some of the extremely immature NHSCs because they lack the ability to adhere to plastic. Using a native extracellular matrix (ECM), produced by bone marrow (BM) stromal cells, the majority of the UCB-NHSCs attached within $4 \mathrm{~h}$. The colonyforming unit fibroblast frequency of these cells was $1.5 \times 10^{4} / 10^{8}$ mononuclear cells, which is at least 4000-fold greater than previously reported for UCB-NHSCs. The phenotype of these cells was fibroblast-like and different from those obtained by plastic adhesion; they formed embryonic body-like clusters that were OCT4-positive and expressed other human embryonic stem cell-related markers. Importantly, when implanted subcutaneously for 8 weeks into immunocompromised mice, these ECM-adherent and expanded NHSCs generated three germ layerderived human tissues including muscle, fat, blood vessel, bone, gland, and nerve. Moreover, injection of these cells into muscle damaged by cryoinjury significantly accelerated muscle regeneration.
\end{abstract}

Conclusions: These results indicate that UCB may be a virtually unlimited source of NHSCs when combined with isolation and expansion on ECM. NHSCs may be a practical alternative to embryonic stem cells for a number of therapeutic applications.

Keywords: Umbilical cord blood, CD146-positive cells, Plastic non-adherent cells, Extracellular matrix-adherent cells, Pluripotent stem cells, Extracellular matrix, Three germ layer tissue formation in vivo

\footnotetext{
*Correspondence: xwdlu@yahoo.com; chenx4@uthscsa.edu

†Equal contributors

${ }^{1}$ Research Division, Department of Comprehensive Dentistry, University of

Texas Health Science Center at San Antonio, San Antonio, TX 78229-3900,

USA

Full list of author information is available at the end of the article
} 


\section{Background}

A practical and reliable source of pluripotent and/or multipotent stem cells holds the key to future stem cell therapies. Despite the great potential shown by human embryonic stem (hES) cells and induced pluripotent stem cells (iPSCs), there are a number of challenges that need to be overcome before they can be widely endorsed for use in large numbers of patients suffering from various aged-related diseases. These challenges include ethical concerns with regard to hES cells, potential long-term safety of transplanted iPSCs, and the considerable level of technical skill and cost associated with preparing both types of cells.

Umbilical cord blood (UCB) not only contains hematopoietic stem cells (HSCs) but also non-hematopoietic stem cells (NHSCs) that can differentiate into many distinct cell types including osteoblasts, chondrocytes, myocytes, endothelial cells, and neurons [1,2]. Based on these findings, UCB has been proposed as an alternative source of mesenchymal stem cells (MSCs) for stem cell-based therapies [3, 4]. Compared to bone marrow (BM), a rich source of MSCs, UCB is widely available in abundance and can be harvested with little harm (i.e., low morbidity/mortality) to the donor $[5,6]$. However, most studies report that the frequency of NHSCs in UCB is extremely low ( $\sim 5$ to 350 out of $10^{9}$ mononuclear cells (MNCs)) [6-9] and, compared to BM-derived MSCs (BM-MSCs), these cells are very difficult to grow in standard culture systems [10-12]. As a result, progress in developing UCB as a source of NHSCs for stem cell-based therapies has been largely thwarted.

Unlike HSCs, there are no reliable cell surface markers that specifically define MSCs or NHSCs. As a result, these cells are routinely obtained from BM and other tissues (e.g., UCB) using a standardized method based on adhesion to tissue culture plastic (TCP) $[8,13-15]$. However, there is evidence that the non-adherent cell population contains a significant number of MSCs and the behavior of these cells is very different from those that adhere to TCP [16-18]. Based on these observations, we hypothesized that UCB contains an extremely immature population of NHSCs that have been previously overlooked because they fail to attach to TCP.

Previously, we reported on the production and characterization of a native extracellular matrix (ECM) generated by BM stromal cells $[19,20]$. This ECM, deposited onto TCP dishes by the cells and subsequently decellularized, is $80-100 \mu \mathrm{m}$ thick and displays a unique tissue-like architecture. It consists of more than 70 different matrix proteins including collagens, fibronectin, small leucine-rich proteoglycans, and several basement membrane components $[19,20]$. MSCs cultured on this BM-derived ECM (BM-ECM) exhibit enhanced attachment, proliferation, and retention of stem cell properties, including differentiation into multiple cell lineages as well as the capacity for skeletogenesis [19-21].

The current study tests the above hypothesis and determines whether BM-ECM facilitates the efficient isolation of UCB-NHSCs by enhancing attachment and proliferation and promoting the retention of their stem cell properties.

\section{Methods}

\section{Isolation and culture of NHSCs from human UCB}

UCB was purchased from South Texas Blood \& Tissue Center (San Antonio, TX, USA). MNCs were isolated from UCB using Ficoll-Paque Premium density media (GE Healthcare Bio-Sciences, Pittsburgh, PA, USA) as described previously [14]. MNCs were suspended in "growth media" containing alpha-minimal essential media ( $\alpha$-MEM; Life Technologies, Grand Island, NY, USA), penicillin $(100 \mathrm{U} / \mathrm{ml})$, streptomycin $(100 \mu \mathrm{g} / \mathrm{ml}$; Biofluids, Rockville, MD, USA), $15 \%$ pre-selected fetal bovine serum (FBS; Becton Dickinson, Franklin Lakes, NJ, USA), L-glutamine (4 $\mathrm{mM})$, and basic fibroblast growth factor (bFGF; $4 \mathrm{ng} / \mathrm{ml}$ ) and seeded at $10^{6} \mathrm{MNCs} /$ $\mathrm{cm}^{2}$ onto TCP that was either uncoated or coated with fibronectin [22] or coated with ECM made by human BM stromal cells $[19,20]$. After seeding, MNC cultures were incubated for $72 \mathrm{~h}$ at $37^{\circ} \mathrm{C}$ to allow for attachment of the cells and then washed twice with phosphatebuffered saline (PBS) to remove non-adherent cells. After washing, growth media were added and half media changes were performed every 3 days. The adherent cells were cultured to $70-90 \%$ confluence in a humidified atmosphere at $37{ }^{\circ} \mathrm{C}$. Adherent cells (passage (P)1) were detached from TCP surfaces using trypsin or the ECM surface using collagenase. An aliquot of the cells (P1) was used to determine the phenotype of the population using flow cytometry (see below), while the remaining cells were either used immediately or stored in liquid nitrogen. Over 100 UCB samples were obtained from the tissue bank and processed for this study. A subset of 50 of these samples was used in the current study because they had been more completely analyzed for cell phenotype.

\section{Human BM cells}

Freshly isolated human BM-MNCs (containing MSCs), obtained from 20- to 30-year-old donors and purchased from ALLCELLS (Emeryville, CA, USA), were used to prepare BM stromal cell-derived ECM (BM-ECM) as described previously [20]. Previously, we demonstrated that BM-ECM is superior to uncoated TCP as a culture surface for human BM-MSCs and promotes attachment, expansion, and "stemness" of these cells [20]. For the present study, human BM-MNCs or MSCs were cultured on this ECM for comparison with UCB-derived cells. 


\section{Flow cytometry}

Anti-CD34, CD45, CD105, and CD146 antibodies were purchased from R\&D Systems (Minneapolis, MN, USA). Anti-CD29 and SSEA-4 antibodies were purchased from BD Bioscience (San Jose, CA, USA). Single-cell suspensions $\left(1-3 \times 10^{5}\right)$ were incubated for $30 \mathrm{~min}$ at $4{ }^{\circ} \mathrm{C}$ in $100 \mu \mathrm{l}$ of specific antibody $(10 \mu \mathrm{g} /$ $\mathrm{ml})$. Antibody-labeled cells were washed twice with staining buffer (PBS containing 5\% fetal calf serum (FCS) and $0.01 \%$ sodium azide) and incubated in $20 \mu \mathrm{g} / \mathrm{ml}$ of FITC-conjugated goat anti-mouse IgG for $20 \mathrm{~min}$ at $4{ }^{\circ} \mathrm{C}$. Cells were then washed two times with staining buffer and either analyzed immediately or fixed with $1 \%$ paraformaldehyde and analyzed within $96 \mathrm{~h}$ using a Becton Dickinson FACStar ${ }^{\text {plus }}$ (Franklin Lakes, NJ, USA) flow cytometer with 10,000 events collected per sample. The percentage of positive cells was determined by fluorescence-activated cell sorting (FACS). All assays were run in parallel using cells stained with isotype IgG as a negative control.

\section{Determination of cell population doubling time (PDT)}

UCB-derived cells (P3-5), previously maintained on ECM, were seeded $\left(4 \times 10^{3}\right.$ cells $\left./ \mathrm{cm}^{2}\right)$ onto ECMcoated plates in growth media and cultured for up to 9 days. At harvest, adherent cells were detached with collagenase and the number of live cells determined in triplicate. The average number of cells for each time point was plotted against time to generate a growth curve. PDT was determined as described previously [23].

\section{Immunohistochemistry}

UCB-derived cells (P2), previously maintained on ECM, were seeded $\left(2.5-7.5 \times 10^{4}\right.$ cells $\left./ \mathrm{cm}^{2}\right)$ onto chamber slides and cultured for 2 days in growth media. The cells were fixed with $4 \%$ formaldehyde for $30 \mathrm{~min}$ at room temperature, washed with PBS, and then blocked for $1 \mathrm{~h}$ using $5 \%$ normal goat serum containing $0.1 \%$ bovine serum albumin (BSA). The cells were stained by incubation with primary antibodies (1:100 dilution) against OCT4, TRA-1-60, and SSEA-4 for $30 \mathrm{~min}$ at $4{ }^{\circ} \mathrm{C}$. Non-specific isotype rabbit IgG (1:100 dilution), mouse IgM (1:100 dilution), and mouse IgG (1:100 dilution) were used as negative controls, respectively. After washing with PBS, samples were incubated for $20 \mathrm{~min}$ with the appropriate FITC-conjugated secondary antibody. Specimens were mounted in DAPI-containing medium (Vector Laboratories, Burlingame, CA, USA) and the cells visualized using an Olympus FV500 Fluoview confocal microscope equipped with image analysis software to quantify fluorescence intensity (Olympus America, Inc., Melville, NY, USA).

\section{Determination of colony-forming unit fibroblast and} osteoblast numbers

To determine the number of colony-forming unit fibroblast (CFU-F) colonies in the initial MNC population, freshly isolated UCB cells were seeded at low seeding density $\left(1 \times 10^{5} \mathrm{MNCs} / \mathrm{cm}^{2}\right)$ onto ECM and uncoated or fibronectin-coated TCP surfaces and cultured at $37{ }^{\circ} \mathrm{C}$ in growth media. Half media changes were performed every 3 days. After 1 month, the cells were fixed and stained with crystal violet to determine CFU-F number. To assess CFU osteoblast (CFU-OB) colony formation, CFU-F colonies were maintained for an additional 25 days in osteoblast differentiation medium (growth media supplemented with $100 \mathrm{nM}$ dexamethasone (Sigma), $50 \mu \mathrm{M} \mathrm{L-}$ ascorbate-2-phosphate (Wako Chemicals, Richmond, VA, USA), and $10 \mathrm{mM}$ glycerol 2-phosphate). CFU-OB colonies were counted after staining with von Kossa.

\section{Adipogenesis and myogenesis}

UCB-derived cells (P1-3), previously maintained on ECM, were seeded $\left(4 \times 10^{3}\right.$ cells $\left./ \mathrm{cm}^{2}\right)$ onto ECM-coated plates in growth media and cultured to confluence. To study adipogenesis, the media were changed at confluence to differentiation media (DMEM containing 10\% FBS, $0.5 \mathrm{mM}$ IBMX, $1 \mu \mathrm{M}$ dexamethasone, $10 \mu \mathrm{g} / \mathrm{ml}$ insulin, $100 \mu \mathrm{M}$ indomethacin) [24] and one-half media changes were performed every 5 days. After 20 days in culture, adipocytes were visualized by staining with Oil Red O. To study myogenesis, the media were changed at confluence to differentiation media (DMEM containing $10 \%$ FBS, 5\% horse serum, $10^{-7} \mathrm{M}$ dexamethasone, $50 \mu \mathrm{M}$ hydrocortisone) [24] and one-half media changes were performed every 5 days. After 25 days in culture, myotubes were identified after staining with hematoxylin and eosin (H\&E).

\section{Cardiomyogenesis and angiogenesis}

Cardiomyogenesis was induced as described previously [25]. Briefly, UCB-derived cells (P2) or BM-MSCs (P2), previously maintained on ECM, were seeded $\left(10^{6}\right.$ cells/ $\mathrm{cm}^{2}$ ) onto TCP and cultured for 2 days in standard growth media, followed by an additional 2 days in media containing $5 \mu \mathrm{M}$ 5-azacytidine (Sigma). Subsequently, the cells were switched to differentiation media (DMEM containing $10 \%$ FBS, $10^{-4} \mathrm{M}$ ascorbic acid (Sigma) and $10 \mathrm{ng} / \mathrm{ml}$ transforming growth factor (TGF)- $\beta$ ) and cultured for up to 25 days with media replaced every 4 days. The expression of cardiac troponin $\mathrm{T}$ type 2 (TNNT2) was quantified using TaqMan polymerase chain reaction (PCR) after culture for 25 days in either growth or differentiation media.

To study angiogenesis, UCB-derived cells (P2), previously maintained on ECM, were seeded $\left(3 \times 10^{3} \mathrm{cells} / \mathrm{cm}^{2}\right)$ onto six-well TCP plates coated with Matrige $^{\text {ma }}$ (BD 
Bioscience, San Jose, CA, USA) in $1 \mathrm{ml}$ endothelial differentiation media (EGM-2; Lonza, Switzerland) and cultured for 7 days at $37^{\circ} \mathrm{C}$. Media changes were performed every 3 days. Capillary formation was documented with brightfield photomicrographs. Baboon endothelial progenitor cells (positive controls) were kindly provided by Dr. Qiang Shi (TBRI, San Antonio). BM-MSCs (P2) were used as negative controls.

\section{Isolation of RNA and gene expression analyses using real-time PCR}

Total RNA was extracted from cultured cells using Ultraspec $^{\text {Ta }}$ RNA (Biotecx, Houston, TX, USA) [19]. RNA $(2 \mu \mathrm{g})$ was reverse-transcribed using a High Capacity cDNA Archive Kit (Applied Biosystems, Foster City, CA, USA). The transcripts of interest, including housekeeping genes (GAPDH or $\beta$-actin), were amplified from the cDNA by real-time PCR using TaqMan Universal PCR Master Mix and TaqMan based primer and probe sets (TaqMan gene Expression assays, Applied Biosystems). Amplification and detection were carried out with an ABI Prism 7500 Sequence Detection System (Applied Biosystems) and gene expression quantified by subtracting the GAPDH threshold cycle $(\mathrm{Ct})$ value from the $\mathrm{Ct}$ value of the gene of interest and expressed as $2^{-\Delta \mathrm{Ct}}$. RNA isolated from hES (ESI6) was kindly provided by Dr. Peter J. Hornsby (UTHSCSA) and served as a positive control.

\section{In vivo implant assay}

Cells $\left(1 \times 10^{6}\right)$ were loaded onto Gelfoam (Pharmacia \& Upjohn Company, MI, USA) or hydroxyapatite/tricalcium phosphate (HA/TCP) particles (Zimmer Inc, Warsaw, IN, USA) and implanted subcutaneously into the dorsal surface of 10-week-old immunodeficient beige mice (NIH-bg-nu-xid; Harlan Sprague Dawley, Indianapolis, IN, USA) [19] according to an approved IACUC protocol at UTHSCSA. After 8 weeks, implants were harvested, fixed, decalcified (HA/TCP implants only), and embedded in paraffin. Sequential sections were processed and stained with H\&E. Bielschowsky's silver stain was used to identify nerve [26]. To determine the origin of neotissues formed during implantation, a section adjacent to the $H \& E$ stained section was stained with an antibody specific for human nuclear ribonucleoprotein (Millipore, Billerica, MA, USA) [27].

\section{Green fluorescent protein labeling}

To prepare ECM-adherent UCB cells stably expressing green fluorescent protein (GFP), commercially available Lentiviral particles (GeneCopoeia Lentifect ${ }^{\mathrm{tm}}$, LP-EGFPLV105-0200) were used as described in the manufacturer's instructions. Cells, labeled with an efficiency of $>70 \%$, were sorted using flow cytometry and $\mathrm{GFP}(+)$ cells ( $95 \%$ positive) were expanded for the experiments.

\section{Muscle regeneration using a cryoinjury animal model}

A model of muscle cryoinjury was established in homozygous immunodeficient RAG2 ${ }^{-1-}, \gamma \mathrm{c}-/-$ mice (Taconic, Germantown, NY, USA) that were maintained as a breeding colony and housed in a temperature-controlled, airfiltered room with a 12-h light-dark cycle. All procedures were performed according to an approved IACUC protocol at UTHSCSA.

Adult mice (8 to 12 weeks old) were anesthetized and the gluteus maximus muscle exposed bilaterally. The oval shaped end $(4 \times 6 \mathrm{~mm})$ of a 12 inch long copper probe was immersed in liquid nitrogen and then applied to the muscle for $20 \mathrm{~s}$. Following cryoinjury, $10^{6} \mathrm{UCB}-$ NHSCs were suspended in $35 \mu \mathrm{l} 50 \%$ Matrigel $^{\mathrm{mm}}(1: 1$ Matrigel $^{\text {ma }}$ to DMEM) and $10 \mu \mathrm{l}$ aliquots of this suspension were implanted intramuscularly in three locations within the injured area, and then the skin was closed. Vehicle $\left(35 \mu \mathrm{l} 50 \%\right.$ Matrigel $\left.^{\mathrm{m}}\right)$ and skin fibroblasts $\left(10^{6}\right.$ cells in $35 \mu \mathrm{l} 50 \%$ Matrigel $\left.^{\mathrm{lw}}\right)$ were used as controls. After 28 days, the animals were euthanized and muscle tissue harvested for histology or snap frozen in liquid nitrogen and stored at $-80{ }^{\circ} \mathrm{C}$.

\section{Statistical analysis}

To successfully predict the isolation of NHSCs from UCB tissue, we initially employed a generalized linear regression model using MATLAB Statistics and Machine Learning Toolbox. The independent variables considered were: UCB sample volume, time since delivery in hours (time between tissue harvest and cell isolation in the laboratory), and cell surface phenotypic markers. The model indicated that all of the variables, except CD146, failed to identify a combination capable of predicting success. Next, we used a stepwise approach which excluded variables that failed to enhance our ability to predict the successful isolation of UCB cells. We began with the generalized linear regression model and then, in stepwise fashion, tested whether removing/adding variable(s) improved predictive power. The final model was arrived at by reaching a point where no single backward or forward step improved the model's predictive accuracy.

All data are presented as the mean \pm standard deviation ( $n=3$ or 6 depending on the experiment). All results were reproduced in at least six independent experiments with cells from six or more donors. For in vivo studies, a total of 18 implants, using cells from six or more donors, were performed. Statistical analyses were performed with the Student's $t$ test or one-way analysis of variance (ANOVA) with significance set at $p<0.05$. 


\section{Results}

\section{MNC phenotype varies widely with UCB donor}

The expression of cell surface markers for HSCs (CD34), MNCs (CD45), endothelial cells (CD31), and MSCs (CD90, CD146, SSEA-4) was routinely measured upon arrival of UCB samples at the laboratory. As experience was gained in analyzing the samples, it became increasingly clear that this initial population of MNCs was very heterogeneous and displayed wide variation in all of the phenotypic markers examined (e.g., CD45: range 0-96\%, median 45\%; CD34: range 0-20\%, median 2.2\%) (Fig. 1a and b). Subsequently, after completing the analysis of all the samples $(n=50)$, it was observed that we had been successful at obtaining UCB-NHSCs in 35\% of the samples. This led us to critically examine the data, focusing on those UCB samples where all markers had been measured, and look for potential attributes of the initial MNC population that increased the likelihood of successfully isolating UCB-NHSCs. The results of performing a generalized linear regression analysis indicated that only CD146 expression was likely to have a non-zero coefficient $(p<0.02)$ (Fig. 1a). Subsequently, a stepwise linear regression was performed and only CD146 expression was found to predict the successful isolation of UCB-NHSCs. Using the equation $p=0.06\left(\% \mathrm{CD} 146^{+}\right)+0.24$ ( $p$ is the probability of success), there is a $50 \%$ likelihood of obtaining UCB-NHSCs, when the MNC population contains $4.33 \% \mathrm{CD} 146^{+}$, with $72 \%$ accuracy (Fig. 1c).

\section{UCB-derived colony-forming cells adhere to ECM but not TCP surfaces}

To determine the effect of culture surface on retrieval of NHSCs, freshly isolated MNCs were plated onto TCP (with or without fibronectin) or ECM and incubated for 4-72 h. At the end of culture, media were removed and the cells washed with PBS to remove non-adherent cells. In Fig. 2a, it can be seen that an abundance of UCBderived fibroblast-like cells attached to the ECM in as little as $4 \mathrm{~h}$. With continued incubation (up to $72 \mathrm{~h}$ ), cell density increased. In contrast, relatively few cells attached to TCP.

The frequency of NHSCs in UCB was measured using CFU-F assays. When MNCs were seeded on ECM at low density $\left(10^{5} \mathrm{MNCs} / \mathrm{cm}^{2}\right)$, the frequency of NHSCs was found to be approximately $1.5 \times 10^{4}$ colonies $/ 10^{8}$ MNCs. This is at least 4000-fold greater than reported by others

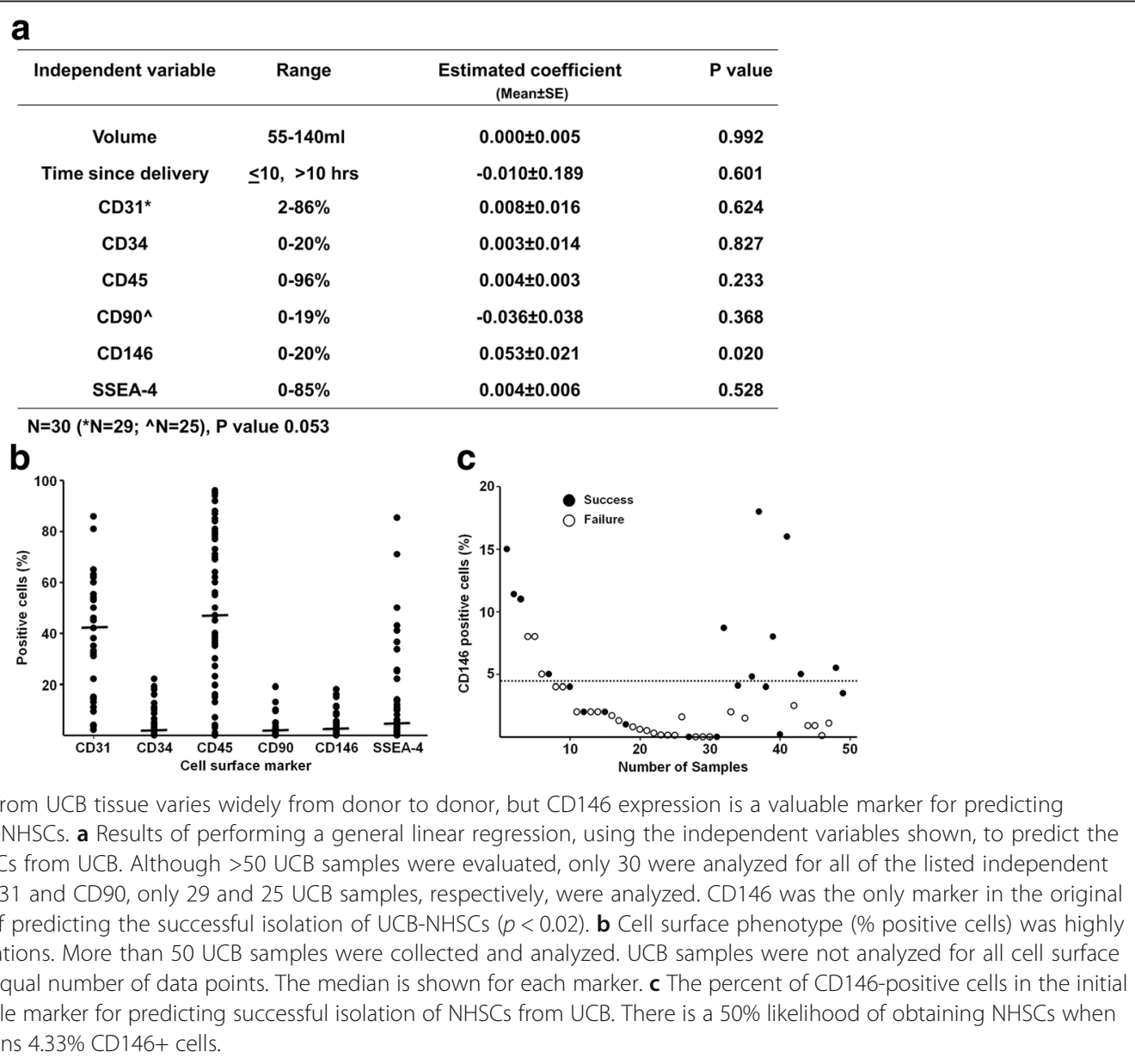



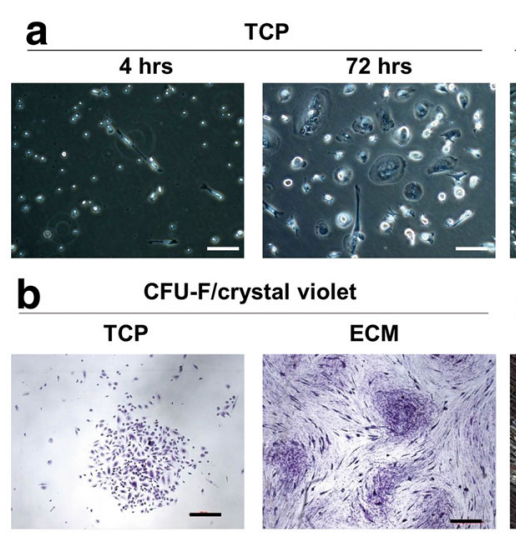

\section{ECM}

\section{Phase contrast (in culture)}

CFU-F EB ECM
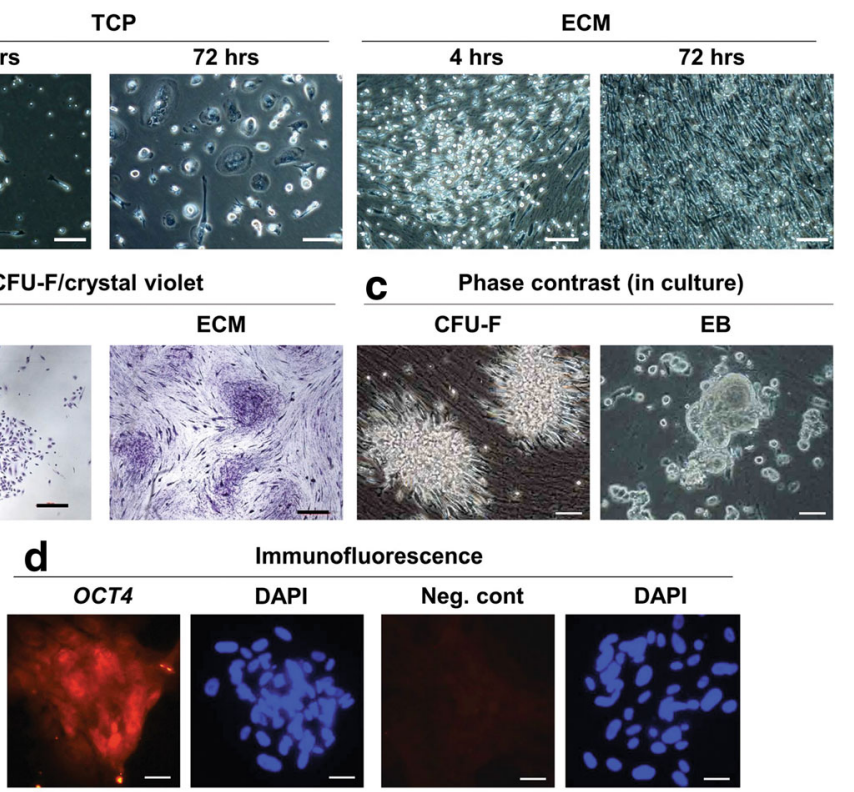

Immunofluorescence
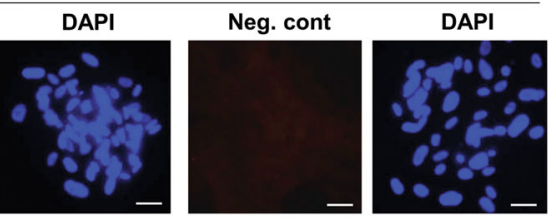

Fig. 2 ECM promotes the attachment and CFU-F formation of UCB-NHSCS. a MNCs were isolated from UCB using a Ficoll-Paque Premium density gradient, seeded $\left(1 \times 10^{6} \mathrm{MNCs} / \mathrm{cm}^{2}\right)$ onto either extracellular matrix $(E C M)$ or uncoated tissue culture plastic $(T C P)$, and incubated at $37^{\circ} \mathrm{C}$ for up to $72 \mathrm{~h}$ as described in the Methods. At harvest, non-adherent cells were removed by washing with PBS and cell attachment to the surfaces recorded photographically under phase contrast microscopy. Scale bar $=100 \mu \mathrm{m}$. b Colony-forming units fibroblast (CFU-F) colony formation by primary (PO) cultures of MNCs on ECM or TCP surfaces. CFU-Fs were fixed and stained with crystal violet. Scale bar $=100 \mu \mathrm{m}$. c Phase contrast microscopy of CFU-Fs in culture. Some areas of the cultures have the appearance of embryonic bodies (EB). Scale bar $=10 \mu \mathrm{m}$. $\mathbf{d}$ OCT4, a marker used to identify ES cells, was expressed by EB formed by the UCB-NHSCs in culture. OCT4 was detected by immunofluorescence. Non-specific isotype lgG was used as a negative control (Neg. cont). Nuclear staining with DAPI is shown in blue. Scale bar $=10 \mu \mathrm{m}$

(Fig. 2b) [6-9]. In addition, cells cultured on ECM generated embryonic body (EB)-like clusters that exhibited OCT4-positive staining, a unique feature of ES cells (Fig. $2 \mathrm{c}$ and $\mathrm{d}$ ). None of these findings were observed on TCP.

To determine if NHSCs were present in the TCP-nonadherent population, we collected non-adherent cells from both surfaces and reseeded them onto ECM (Fig. 3). After $24 \mathrm{~h}$, more of the TCP non-adherent cells were found attached to the ECM than previously non-adherent to the ECM (H\&E stain) (Fig. 3a and b). Importantly, there was a 10-fold greater number of cells attached to the ECM, after originally being non-adherent to TCP, as compared to those previously non-adherent to the ECM (Fig. 3e). When culture on ECM was continued for CFU-F assay, the TCP-non-adherent cells produced $\sim 10^{4}$ colonies $/ 10^{8}$ MNCs (Fig. 3c) while the ECM-non-adherent
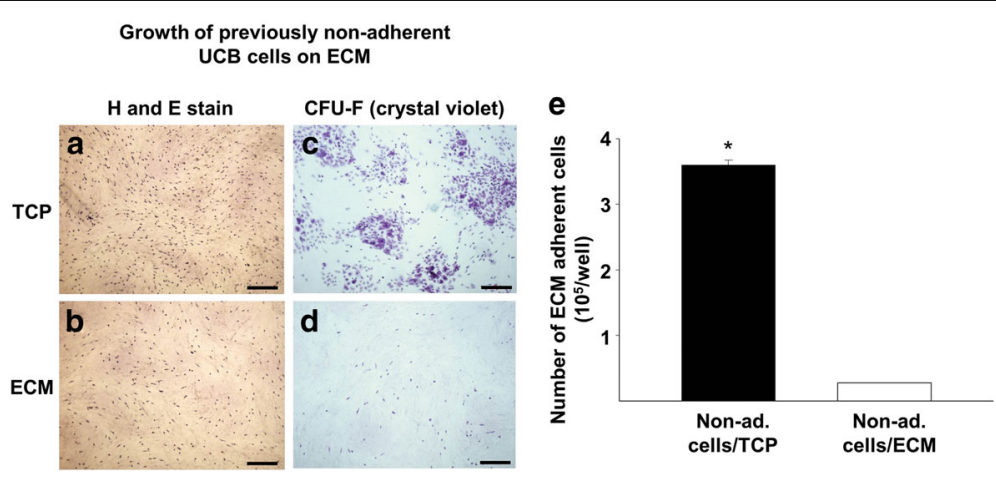

Fig. 3 Large numbers of colony-forming cells can be recovered from cultures of TCP-non-adherent UCB-NHSCs by growth on ECM. Non-adherent (Non-ad.) UCB-NHSCs were collected from uncoated tissue culture plastic (TCP) or extracellular matrix (ECM) after $72 \mathrm{~h}$ of culture and then reseeded onto ECM plates. To visualize cell attachment to the ECM (after $24 \mathrm{~h}$ of culture), non-adherent cells were removed by washing with PBS and the remaining adherent cells stained with hematoxylin and eosin $(H$ and E) $(\mathbf{a}, \mathbf{b})$. For colony-forming unit fibroblast (CFU-F) assay, the reseeded cells were cultured for 1 month on ECM, and then fixed and stained with crystal violet (c, d). Scale bar $=100 \mu \mathrm{m}$. e Number of UCB-NHSCs, previously non-adherent to uncoated TCP or ECM, collected after a second culture (rescued) on ECM for $24 \mathrm{~h} .{ }^{*} p<0.05$ 
group produced far less (Fig. 3d). Interestingly, the number of colonies generated by TCP-non-adherent cells, rescued on ECM, approximated that generated by cells initially seeded on ECM $\left(1.0 \times 10^{4}\right.$ colonies $/ 10^{8}$ MNCs vs. $1.5 \times 10^{4}$ colonies $/ 10^{8} \mathrm{MNCs}$, respectively). These results clearly suggest that UCB contains a large number of colony-forming cells that preferentially attach to ECM.

\section{ECM-adherent UCB-NHSCs display a pluripotent stem cell phenotype in vitro}

To determine the expansion capacity of NHSCs, cells were seeded at the same density on the different culture surfaces and grown for 1 month. At the end of culture, cells on ECM were confluent, fibroblast-like, and spindle-shaped (Fig. 4a). In contrast, cells on TCP (with or without fibronectin) grew poorly and failed to reach confluence. Cells that attached and grew on TCP were round, flat, and contained an abundance of cytoplasmic vacuoles suggestive of autophagy [28].

The phenotype of cells that grew on ECM was quite different from those on TCP. Expression of SSEA-4, a hES cell marker [29, 30], was found on $50 \%$ of the cells. In addition, a number of MSC-related markers, but not HSC markers, were expressed by $80-90 \%$ of the cells (Fig. 4b) [15]. The cells grew vigorously through 10 passages. P5 cells, shown in Fig. 4c, have a population doubling time of $29 \mathrm{~h}$ during the first 5 days in culture.

To further define the phenotype of NHSCs cultured on ECM, we examined genes strongly expressed by hES cells [30]. NHSCs were found to express NANOG, OCT4, TDGF1, DNMT3B, GABRB3, Sox2, and LIN28 at 5-, 7-, 17-, 10-, 1.9-, 47- and 38-fold higher levels, respectively, than BM-MSCs obtained using the same ECM culture system (Fig. 5a). Unfortunately, it was impossible to obtain enough cells from TCP cultures to conduct the experiment. To confirm the expression of hES-associated genes by the NHSCs at the protein level, we immunostained cells using antibodies specific for OCT4, SSEA-4, and TRA-1-60 (Fig. 5b). In agreement with the gene expression data, NHSCs strongly expressed these ES cell-related markers as compared to BM-MSCs (Fig. 5b). These results suggest that UCBNHSCs were a unique population of cells with characteristics of both MSCs and ES cells.

The differentiation capacity of UCB cells (P1 to P3) obtained by culture on ECM or TCP was examined by reseeding onto ECM or TCP and culturing to confluence. The cells were then switched to various differentiation media. UCB-NHSCs grown on ECM with adipogenic media differentiated into adipocytes (Fig. 6a). Similarly,

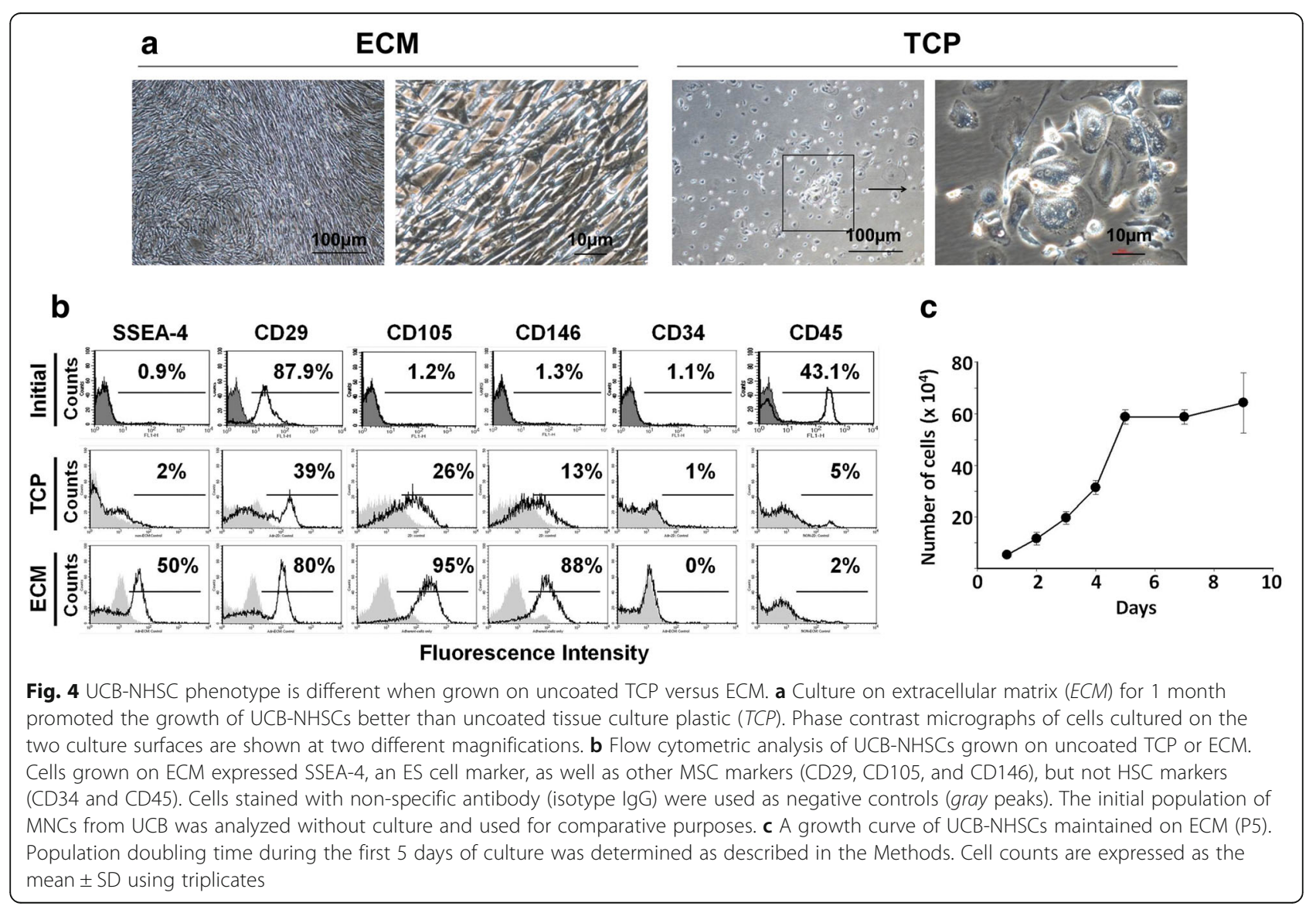




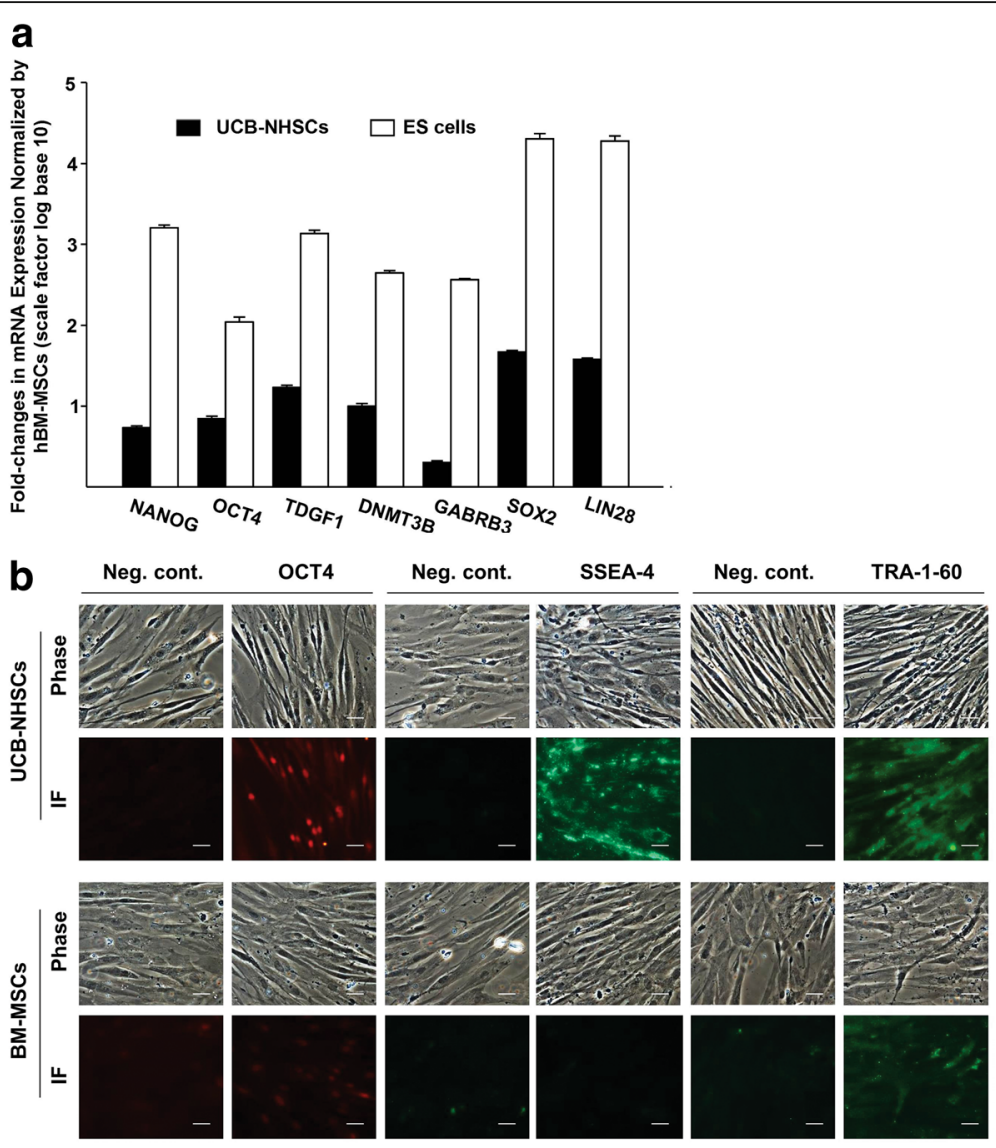

Fig. 5 ECM-adherent UCB-NHSCs express ES cell markers. a The gene expression profile of P2 umbilical cord blood-derived non-hematopoietic stem cells (UCB-NHSCS) cultured on ECM was determined using TaqMan PCR. RNA isolated from human embryonic stem (ES) (ESI6) cells was used as a positive control, while RNA harvested from human bone marrow-derived mesenchymal cells (hBM-MSCs) was used for normalization of the data. All three types of cells were prepared, cultured on ECM, and harvested in parallel. The data shown represent the mean \pm SD fold-changes (note: $\log$ base 10 scale on y axis) in transcript level after normalization to that of BM-MSCs. $\mathbf{b}$ Immunofluorescent (IF) detection of OCT4, SSEA-4, and TRA-1-60. UCB-NHSCS (P2) pre-cultured on ECM were seeded $\left(2.5-7.5 \times 10^{4} \mathrm{cell} / \mathrm{s} / \mathrm{cm}^{2}\right)$ onto regular chamber slides and cultured for 2 days. Cells were immunostained with antibodies specific for the proteins of interest. Non-specific isotype rabbit lgG, mouse lgG, and mouse lgM were used as negative controls (Neg. cont.) for OCT4, SSEA-4, and TRA-1-60, respectively. Parallel cultures of BM-MSCs were also prepared and treated similarly. Phase contrast micrographs of both types of cells are shown for comparative purposes. Scale bar $=10 \mu \mathrm{m}$

cells in myogenic media differentiated and formed myotubes (Fig. 6b), while cells on TCP failed to grow. To test the cardiomyogenic potential of ECM-adherent UCB-NHSCs, confluent cells (P2) were maintained in differentiation media and the expression of TNNT2 [25] measured. The results showed that TNNT2 expression by the differentiated cells was increased 189 -fold compared to untreated controls (Fig. 6c). In contrast, TNNT2 expression by BM-MSCs, similarly treated, was only increased 28 -fold with induction. Interestingly, the basal level of TNNT2 expression by ECM-adherent UCB-NHSCs was 19-fold higher than the BM-MSCs and in differentiation media the difference between the two types of cells was increased to 100-fold (Fig. 6c). Confluent NHSCs (P2) maintained on ECM in osteogenic media stained strongly with von Kossa (Fig. 6d). In contrast, no mineralization was observed with cells on TCP. To determine the angiogenic potential of the cells, UCB-NHSCs were seeded onto Matrigel-coated wells and evaluated for their ability to form microvasculature [31]. Surprisingly, UCB-NHSCs produced a capillary-like network within 48 h (Fig. 6e), which was significantly faster than observed with endothelial progenitors (positive controls) (data not shown).

\section{ECM-adherent UCB-NHSCs display a pluripotent phenotype and generate tissues in vivo}

To evaluate the ability of UCB-NHSCs to generate tissue in vivo, cells were loaded onto scaffolds and the cellloaded scaffolds implanted subcutaneously in immunocompromised mice for 8 weeks. At harvest, the implants were processed for histology. Interestingly, implants loaded with UCB cells, obtained from the ECM culture system, generated multiple tissues originating from three 


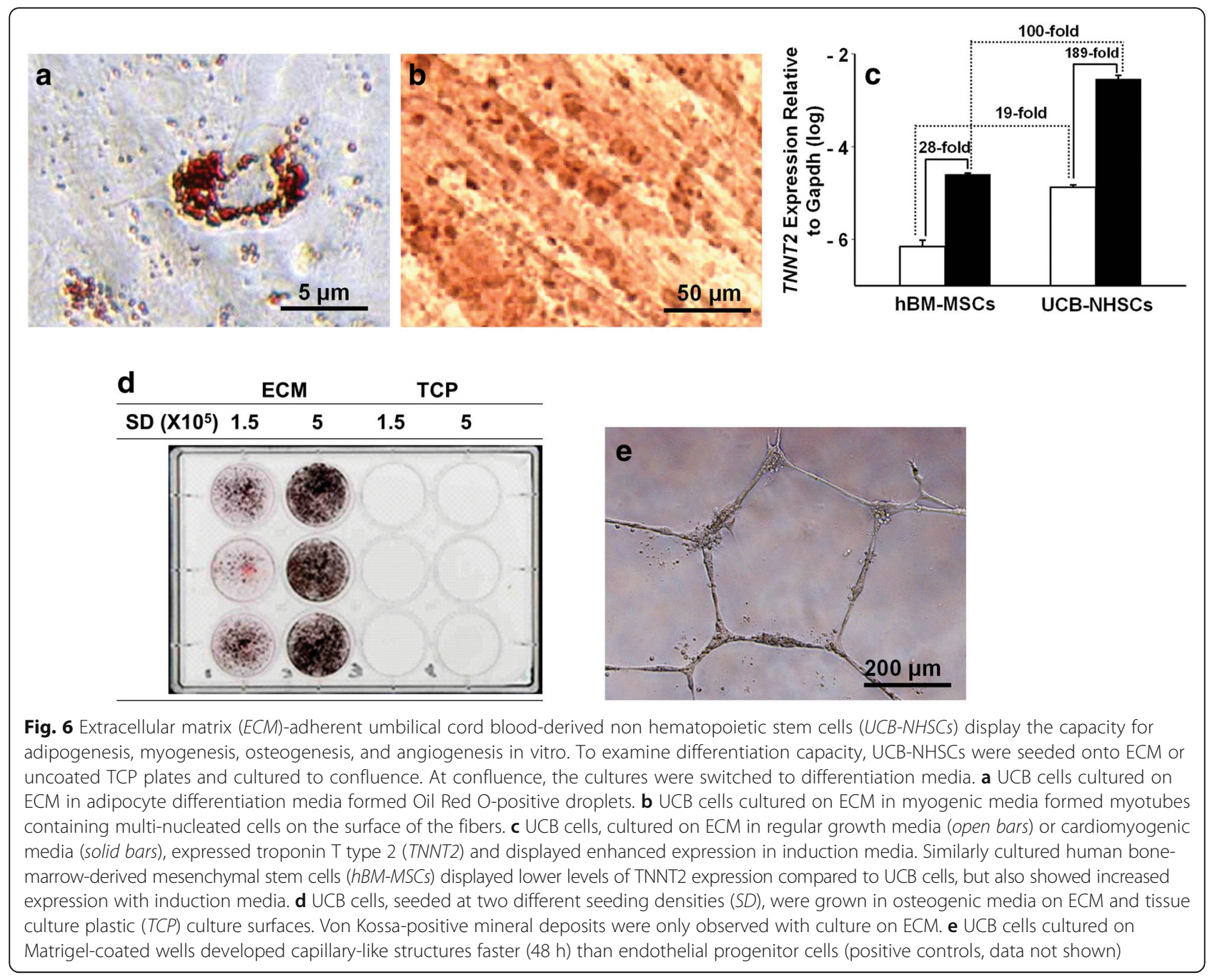

germ layers (mesoderm: muscle, fat, blood vessel and bone; endoderm: gland; ectoderm: nerve) (Fig. 7a). To determine the cellular origin of the newly formed tissues, histological sections adjacent to those stained with $H \& E$ were immunostained with an antibody specific for human nuclear ribonucleoprotein [27]. Clearly, cells within the newly-formed tissues indicated their human origin (Fig. 7a, except for bone). Mouse and human tissues were used as negative and positive controls, respectively (data not shown). Skeletal tissue, found in ossicles within the implants, were of human origin [32]. Nerve tissue was specifically identified using Bielschowsky's silver staining. In parallel, we also implanted scaffolds with or without BM-MSCs and found no heterogeneous tissue formation (Fig. 7b).

ECM-adherent UCB-NHSCs have the capacity to regenerate skeletal muscle after cryoinjury

Based on studies showing that ECM-adherent UCBNHSCs were able to generate muscle and blood vessels in vitro and after in vivo implantation, we tested the ability of these cells to regenerate skeletal muscle after cryoinjury. In this wound model, muscle injury is caused by touching a pre-cooled probe onto the gluteus maximus.

For the current experiments, ECM-adherent NHSCs were suspended in vehicle and then injected into each of three locations in the injured muscle. Another wound site was similarly injected with vehicle alone or skin fibroblasts as negative controls. After 28 days, the lesion area was measured on histological slides (Fig. 7c) and found to be decreased in wounds treated with NHSCs compared to vehicle- or skin fibroblast-treated controls. Although myogenic cells infiltrated the area around the edge of the wound, the number of myogenic cells $(91 \pm 7)$ was significantly higher in wounds injected with ECM-adherent cells compared to vehicle alone $(72 \pm 5)$ (Fig. 7d). Interestingly, instead of new muscle tissue, adipose tissue was observed in lesions treated with vehicle or skin fibroblasts. To identify the 


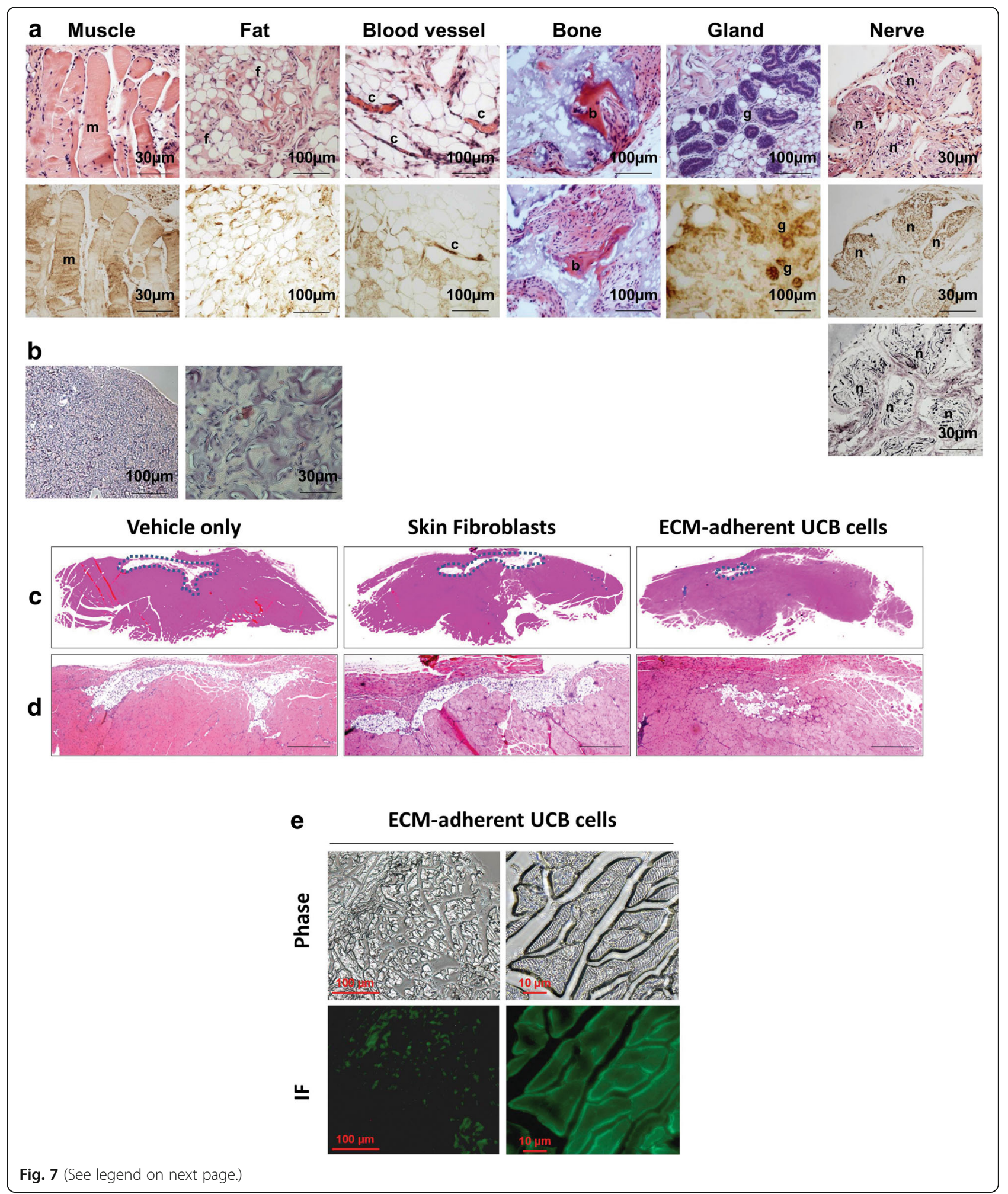




\begin{abstract}
(See figure on previous page.)
Fig. 7 ECM-adherent UCB-NHSCs display a pluripotent phenotype and the capacity to regenerate skeletal muscle after cryoinjury. a ECM-adherent NHSCs were loaded onto Gelfoam or HATCP particles and implanted subcutaneously into immunodeficient mice. Implants were harvested after 8 weeks, processed for histological analysis, and stained with H\&E (upper panels); Bielschowsky's silver stain was used to identify nerve (see lower panel of "Nerve") [26]. Sections were also immunostained for human nuclear ribonucleoprotein to confirm the origin of the cells responsible for neotissue formation (see middle row of panels except "bone") [27]. Skeletal tissue (Bone) is only stained with H\&E. Key to labels: $a$, artery; b, bone; c, capillary; e, endothelial cells; $f$, fat; $g$, gland; $m$, muscle; and $n$, nerve. b BM-MSCs were loaded onto Gelfoam carriers and implanted as controls. All procedures for experimental and control groups were performed at the same time. H\&E stained sections demonstrated that BM-MSCs did not form heterogeneous tissues. c Histological cross sections of cryoinjured muscle tissue from immunodeficient mice treated with Matrigel alone (vehicle), Matrigel containing skin fibroblasts, or Matrigel containing extracellular matrix (ECM)-adherent umbilical cord blood (UCB) cells for 28 days. The perimeter of the wound is demarcated using dark blue dots. $\mathbf{d}$ Tissue morphology after H\&E staining. UCB cells resulted in healing and a greater number of myogenic cells around the wound. Scale bar $=100 \mu \mathrm{m}$. e GFP-labelled UCB cells were injected into cryoinjured muscle to confirm that the cells were of human origin. Immunofluorescent (IF) staining demonstrated muscle regeneration by the labeled cells
\end{abstract}

origin of myogenic cells in the newly-formed tissue, GFP-labeled UCB-NHSCs were injected into wound sites. The results clearly reveal that new muscle was produced by the implanted cells (Fig. 7e).

\section{Discussion}

In the present study, we examined more than $50 \mathrm{UCB}$ samples and achieved a 35\% success rate of obtaining NHSCs which is similar to that reported by others [33, 34]. The data support the idea that these cells originated within the UCB and were not the result of "contamination" during collection. The relative lack of success in retrieving NHSCs may be explained by the large phenotypic variation found in the UCB samples and exemplified by the broad range of CD45 positive cells ( 0 to $96 \%$; median, 45\%) (Fig. 1a and b). The expression of this marker is especially informative since CD45 ("leukocyte common antigen") is routinely used to define populations of MNCs from peripheral blood and BM and shows that these tissues are quite variable. To further assess the quality and variation of the UCB samples, we also examined the expression of CD34, a HSC marker. In the current study, the percentage of CD34-positive cells in the UCB MNCs was fairly low (range, 0 to 20\%; median, $2.2 \%$ ), but in the range previously reported for HSCs from peripheral blood and BM [35, 36].

Since UCB volume and "freshness" (i.e., time from delivery/parturition to cell isolation) have been suggested to predict the successful isolation of UCB cells [34], we included these two parameters, along with cell surface markers (Fig. 1a), in our general linear regression analysis to determine which combination of attributes more accurately predict success at retrieving NHSCs. It was found that CD146 expression was the only factor that correlated with success; the higher the percentage of CD146 in the population, the greater the chance of successfully isolating NHSCs. If CD146 expression reaches $4.33 \%$, the chance of success will be $50 \%$. Such a correlation may be explained by the fact that CD146 is a marker for pericytes which have been proposed to give rise to MSCs [37]. However, CD146-positive cells, isolated from the initial population of MNCs by cell sorting, failed to grow (data not shown). The fact that a high initial seeding density is required to stimulate NHSC growth suggests that other cells, such as MNCs, are needed. Nevertheless, the data indicate that in future studies it will be possible to increase our success rate by pre-selecting UCB samples with levels of CD146 expression above the threshold derived here (e.g., 4.33\%).

One of the hypotheses of the current study is that the adhesion capacity of extremely immature NHSCs is poor. Indeed, our data strongly demonstrate that the majority of NHSCs fail to attach to TCP using classical methods for obtaining stem cells. In this study, NHSCs attached to ECM and grew rapidly for up to 10 passages, with a cell PDT of $29 \mathrm{~h}$, when both the ECM and our modified expansion medium were provided. The NHSC population obtained using ECM was different from that obtained with TCP. The former consisted of a large number of stem cells that expressed SSEA-4, a hES cell marker, and MSC-related markers (e.g., CD29, CD105, and CD146) that were not found in the latter. It is widely accepted that attachment of primary NHSCs is a critical first step that must occur before they become activated. In our earlier studies, BM-MSCs grown on BMECM demonstrated both increased cell proliferation and retention of stem cell properties [19-21]. Here, the ECM-based cell culture system not only enriched the number of pluripotent stem cells obtained, but also facilitated the rapid expansion of these cells so that large quantities of high-quality stem cells could be recovered.

Interestingly, our results showed that the frequency of UCB-NHSCs was much higher than that of UCB-HSCs $\left(1 / 10^{4}-10^{5} \mathrm{MNCs}\right)$. Since CD146 expression was the only factor that statistically correlated with successfully isolating UCB-NHSCs, it is likely that UCB-NHSCs are associated with pericytes located along the endothelial lining of capillaries.

To definitively evaluate stem cell self-renewal and pluripotency, in vivo studies are required. More specifically, it is essential to demonstrate that the cells spontaneously form multiple tissues from three germ layers in 
vivo without the use of differentiation-inducing agents [38]. Previously, "embryonic-like stem cells" from UCB were identified based on the expression of several markers associated with pluripotency without in vivo validation [14, 39]. However, marker expression, either at the mRNA or protein level, is not sufficient to demonstrate true stem cell pluripotency [40]. In particular, in vitro differentiation, induced by high concentrations of various reagents, is subject to artifact and a high level of false positives [41]. Our in vivo studies clearly indicate that UCB-NHSCs, obtained using the ECM culture system without inducing agents, were able to generate tissues from the three germ layers. Whether these heterogeneous tissues were generated from authentic pluripotent stem cells or lineage-committed cells remains to be clarified. Since the in vivo results showed that UCB-NHSCs generated enormous amounts of muscle and blood vessels, we further evaluated the capacity of these cells to repair skeletal muscle using a cryoinjury model. The results, using GFP-labeled UCB-NHSCs, showed that the majority of the newly-formed muscle was generated by the labeled NHSCs. In addition, the injected UCB-NHSCs may also recruit endogenous muscle progenitor cells to participate in tissue repair and this may explain the finding that some newly-formed muscle was not stained with GFP. Consistent with this idea, others have previously reported that transplanted MSCs have the capacity to reactivate endogenous stem cells in other organs [42, 43].

In our in vivo studies with NHSCs, teratoma formation was never observed. This may be explained by the modest expression of various ES cell-related genes, such as LIN28 which is associated with the promotion of human cancers $[44,45]$. In the present study, LIN28 expression by ECMadherent UCB-NHSCs was much lower than that of hES cells, even though it was about 37 -fold higher than that of BM-MSCs. Ontologically, our findings suggest that NHSCs, obtained using the ECM, are closer to hES cells than BM-MSCs.

Although hES cells exhibit unlimited self-renewal and the capacity to differentiate into tissues from all three germ layers, the source (human embryos) of these cells raises ethical issues that restrict them from becoming a viable cell-based therapy. A number of the challenges associated with hES cells may be resolved by using iPSCs $[46,47]$. However, iPSC technology is still in its infancy and there are many technical barriers to overcome before they can be used therapeutically $[48,49]$. Here we report a new approach that enables the isolation of natural and highly multipotent NHSCs from an unlimited source, UCB, and that provides sufficient amounts of cells for systematic characterization. Given that the global birth rate is around 100 million per year [50], UCB remains the largest source of stem cells available. This virtually unlimited source of NHSCs makes them a viable alternative to hES cells for cell-based clinical applications. The information gained from this study will likely motivate the development of additional in vivo models for evaluating the use of NHSCs in various clinical applications.

\section{Conclusions}

The results reported here support the existence of embryonic-like stem cells or highly primitive NHSCs in UCB [39, 51]. Importantly, the present study showed that: 1) the frequency of UCB-NHSCs is at least 4000-fold greater than that previously reported by others $[6,7,9] ; 2)$ ECM-adherent UCB-NHSCs form embryonic bodies that are OCT4-positive and express other hES cell-related markers; 3) UCB-NHSCs generate multiple tissues that originate from three embryonic germ layers in vivo; and 4) UCB-NHSCs accelerate skeletal muscle regeneration after cryoinjury. To the best of our knowledge, this is the first report that describes a method for successfully isolating substantial quantities of NHSCs from UCB and provides a characterization of these cells.

\section{Abbreviations \\ a-MEM: Alpha-minimal essential media; ANOVA: Analysis of variance; bFGF: Basic fibroblast growth factor; BM: Bone marrow; BM-ECM: Bone marrow-derived extracellular matrix; BM-MSC: Bone marrow-derived mesen- chymal stem cell; CD: Cluster of differentiation; CFU: Colony-forming unit; CFU-F: Colony-forming unit fibroblast; CFU-OB: Colony-forming unit osteoblast; DMEM: Dulbecco's modified Eagle medium; DNA: Deoxyribonucleic acid; ECM: Extracellular matrix; FACS: Fluorescence-activated cell sorting; FBS: Fetal bovine serum; FCS: Fetal calf serum; FITC: Fluorescein isothiocyanate; GAPDH: Glyceraldehyde-3-phosphate dehydrogenase; GFP: Green fluorescent protein; H\&E: Hematoxylin and eosin; HA: Hydroxyapatite; HA/ \\ TCP: Hydroxyapatite/Tricalcium phosphate; hES: Human embryonic stem; HSC: Hematopoietic stem cell; iPSC: Induced pluripotent stem cell; MNC: Mononuclear cell; MSC: Mesenchymal stem cell; NHSC: Non- hematopoietic stem cell; P: Passage; PBS: Phosphate-buffered saline; PCR: Polymerase chain reaction; PDT: Population doubling time; RNA: Ribonucleic acid; Runx2: Runt-related transcription factor-2; SSEA- 4: Stage-specific embryonic antigen-4; TCP: Tissue culture plastic (polystyrene); TNNT2: Troponin T type 2; UCB: Umbilical cord blood}

\section{Acknowledgements}

We give special thanks to Dr. Peter J. Hornsby (Department of Physiology and the Barshop Institute for Longevity and Aging Studies, UTHSCSA) and Dr. Qiang Shi (Texas Biomedical Research Institute, San Antonio) for providing the hES cells (ESI6) and baboon endothelial progenitor cells, respectively.

\section{Funding \\ This work was supported by the University Research Council Grants Program at the University of Texas Health Science Center at San Antonio (UTHSCSA) (X-DC) and a VA Merit Review (X-DC) (1 101 BX000580). The funding agencies did not participate in the design of the study, collecting, analyzing or interpreting the data, or writing the manuscript. Confocal images were generated in the Optical Imaging Core Facility which is supported by UTHSCSA, NIH-NCI P30 CA54174 (San Antonio Cancer Institute), NIH-NIA P30 AG013319 (Nathan Shock Center), and NIH-NIA P01 AG19316.}

\section{Availability of data and materials}

The data that support the findings of this study are available from the corresponding author upon reasonable request. 


\section{Authors' contributions}

JW: collection and/or assembly of data (ECM preparation, long-term cell cultures, primary colony assays, cardiomyogenesis studies), final approval of manuscript. YS: collection and/or assembly of data (ECM preparation, cardiomyogenesis studies, CFU assays, immunohistochemistry), final approval of manuscript. TJB: collection and/or assembly of data, data analysis (MATLAB Statistics and Machine Learning Toolbox), manuscript writing, final approval of manuscript. MM: collection and/or assembly of data, data analysis (MATLAB Statistics and Machine Learning Toolbox), manuscript writing, final approval of manuscript. Z-LZ: collection and/or assembly of data (FACS analyses, PCR, in vivo studies), data analysis, final approval of manuscript. YY: collection and/or assembly of data (FACS analyses, PCR, implantation of UCB cells), final approval of manuscript. RC: collection and/or assembly of data (GFP labeling of UCB-NHSCs, cardiomyogenesis assays), final approval of manuscript. JS: collection and/or assembly of data (GFP labeling of UCB-NHSCs, cryoinjury in vivo experiments), final approval of manuscript. DDD: data analysis and interpretation, manuscript writing, final approval of manuscript. ZL: conception and design, collection and/or assembly of data, data analysis and interpretation, final approval of manuscript. X-DC: conception and design, financial support, data analysis and interpretation, manuscript writing, final approval of manuscript. All authors have read and approved the final version of the manuscript and agree to be accountable for all aspects of the work.

\section{Competing interests}

$X-D C$ is a board member of and shareholder in StemBioSys, Inc. (San Antonio,

TX, USA). The remaining authors declare that they have no competing interests.

\section{Ethics approval and consent to participate}

IRB approval: Human UCB was purchased from the South Texas Blood and Tissue Center (San Antonio, TX, USA) and bone marrow MNCs were purchased from ALLCELLS (Emeryville, CA, USA). In both cases, informed consent was obtained from donors and in compliance with all federal regulations. IACUC approval: In vivo implant studies using immunodeficient beige mice (Harlan) and muscle regeneration after cryoinjury studies using immunodeficient $\mathrm{RAG}^{---}$mice (Taconic) were performed according to IACUC protocols approved by UTHSCSA.

\section{Author details}

${ }^{1}$ Research Division, Department of Comprehensive Dentistry, University of Texas Health Science Center at San Antonio, San Antonio, TX 78229-3900, USA. ${ }^{2}$ Department of Orthodontics, Fourth Military Medical University, School of Stomatology, Xi'an, Shaanxi Province 710032, People's Republic of China. ${ }^{3}$ Center for Reproductive Medicine, Ren-Ji Hospital, School of Medicine, Shanghai Jiao-Tong University, Shanghai 200135, People's Republic of China. ${ }^{4}$ Department of Biomedical Engineering, University of Texas at San Antonio, San Antonio, TX 78249, USA. ${ }^{5}$ Department of Plastic Surgery, Ren-Ji Hospital, Shanghai Jiao-Tong University School of Medicine, Shanghai, People's Republic of China. ${ }^{6}$ Biomedical Materials Engineering Research Center, Wuhan University of Technology, Wuhan, People's Republic of China. ${ }^{7}$ Department of Surgery, University of Texas Health Science Center at San Antonio, San Antonio, TX 78229-3900, USA. ${ }^{8}$ Research Service, Audie L. Murphy Division, South Texas Veterans Health Care System, San Antonio, TX 78229-4404, USA.

\section{Received: 17 August 2016 Revised: 24 October 2016} Accepted: 8 November 2016 Published online: 01 December 2016

\section{References}

1. Goodwin HS, Bicknese AR, Chien SN, et al. Multilineage differentiation activity by cells isolated from umbilical cord blood: expression of bone, fat, and neural markers. Biol Blood Marrow Transplant. 2001;7(11):581-8.

2. Sarugaser R, Lickorish D, Baksh D, et al. Human umbilical cord perivascular (HUCPV) cells: a source of mesenchymal progenitors. Stem Cells. 2005; 23(2):220-9.

3. El-Badri NS, Hakki A, Saporta S, et al. Cord blood mesenchymal stem cells: potential use in neurological disorders. Stem Cells Dev. 2006;15(4):497-506.

4. Arien-Zakay H, Lazarovici $P$, Nagler A. Tissue regeneration potential in human umbilical cord blood. Best Pract Res Clin Haematol. 2010;23(2):291-303.

5. Chang YJ, Shih DT, Tseng CP, et al. Disparate mesenchyme-lineage tendencies in mesenchymal stem cells from human bone marrow and umbilical cord blood. Stem Cells. 2006;24(3):679-85.
6. Kern S, Eichler H, Stoeve J, et al. Comparative analysis of mesenchymal stem cells from bone marrow, umbilical cord blood, or adipose tissue. Stem Cells. 2006;24(5):1294-301.

7. Campagnoli C, Roberts IA, Kumar S, et al. Identification of mesenchymal stem/progenitor cells in human first- trimester fetal blood, liver, and bone marrow. Blood. 2001;98(8):2396-402.

8. Degistirici O, Jager M, Knipper A. Applicability of cord blood-derived unrestricted somatic stem cells in tissue engineering concepts. Cell Prolif. 2008;41(3):421-40.

9. Markov V, Kusumi $K$, Tadesse MG, et al. Identification of cord blood-derived mesenchymal stem/stromal cell populations with distinct growth kinetics, differentiation potentials, and gene expression profiles. Stem Cells Dev. 2007;16(1):53-73.

10. Pozzi S, Lisini D, Podesta M, et al. Donor multipotent mesenchymal stromal cells may engraft in pediatric patients given either cord blood or bone marrow transplantation. Exp Hematol. 2006;34(7):934-42.

11. Solves $P$, Mirabet $V$, Planelles $D$, et al. Influence of volume reduction and cryopreservation methodologies on quality of thawed umbilical cord blood units for transplantation. Cryobiology. 2008;56(2):152-8.

12. Peters $R$, Wolf MJ, van den Broek M, et al. Efficient generation of multipotent mesenchymal stem cells from umbilical cord blood in stroma-free liquid culture. PLoS One. 2010;5(12):e15689.

13. Erices $A$, Conget $P$, Minguell JJ. Mesenchymal progenitor cells in human umbilical cord blood. Br J Haematol. 2000;109(1):235-42.

14. McGuckin C, Jurga M, Ali H, Strbad M, et al. Culture of embryonic-like stem cells from human umbilical cord blood and onward differentiation to neural cells in vitro. Nat Protoc. 2008;3(6):1046-55.

15. Rebelatto CK, Aguiar AM, Moretao MP, et al. Dissimilar differentiation of mesenchymal stem cells from bone marrow, umbilical cord blood, and adipose tissue. Exp Biol Med (Maywood). 2008;233(7):901-13.

16. Modder UI, Khosla S. Skeletal stem/osteoprogenitor cells: current concepts, alternate hypotheses, and relationship to the bone remodeling compartment. J Cell Biochem. 2008;103(2):393-400.

17. Di MN, Mehrkens A, Papadimitropoulos A, et al. Fibroblast growth factor-2 maintains a niche-dependent population of self-renewing highly potent non-adherent mesenchymal progenitors through FGFR2c. Stem Cells. 2012;30(7):1455-64.

18. Akiyama $\mathrm{K}$, You YO, Yamaza $\mathrm{T}$, et al. Characterization of bone marrow derived mesenchymal stem cells in suspension. Stem Cell Res Ther. 2012;3(5):40.

19. Chen XD, Dusevich $V$, Feng JQ, et al. Extracellular matrix made by bone marrow cells facilitates expansion of marrow-derived mesenchymal progenitor cells and prevents their differentiation into osteoblasts. J Bone Miner Res. 2007;22(12):1943-56.

20. Lai $Y$, Sun $Y$, Skinner CM, et al. Reconstitution of marrow-derived extracellular matrix ex vivo: a robust culture system for expanding largescale highly functional human mesenchymal stem cells. Stem Cells Dev. 2010;19(7):1095-107.

21. Sun Y, Li W, Lu Z, et al. Rescuing replication and osteogenesis of aged mesenchymal stem cells by exposure to a young extracellular matrix. FASEB J. 2011;25(5):1474-85.

22. Cukierman E, Pankov R, Stevens DR, et al. Taking cell-matrix adhesions to the third dimension. Science. 2001;294(5547):1708-12.

23. Roth V. Calculating doubling time. 2006. http//www doubling-time com/ compute.php

24. Zuk PA, Zhu M, Mizuno $H$, et al. Multilineage cells from human adipose tissue: implications for cell-based therapies. Tissue Eng. 2001;7(2):211-28.

25. Smits $\mathrm{AM}$, van Vliet $\mathrm{P}$, Metz $\mathrm{CH}_{\text {, et }}$ al. Human cardiomyocyte progenitor cells differentiate into functional mature cardiomyocytes: an in vitro model for studying human cardiac physiology and pathophysiology. Nat Protoc. 2009;4(2):232-43.

26. Hall ED, Sullivan PG, Gibson TR, et al. Spatial and temporal characteristics of neurodegeneration after controlled cortical impact in mice: more than a focal brain injury. J Neurotrauma. 2005;22(2):252-65.

27. Huang NF, Sievers RE, Park JS, et al. A rodent model of myocardial infarction for testing the efficacy of cells and polymers for myocardial reconstruction. Nat Protoc. 2006;1(3):1596-609.

28. Dunn Jr WA. Autophagy and related mechanisms of lysosome-mediated protein degradation. Trends Cell Biol. 1994;4(4):139-43.

29. Kannagi R, Cochran NA, Ishigami F, et al. Stage-specific embryonic antigens (SSEA-3 and -4) are epitopes of a unique globo-series ganglioside isolated from human teratocarcinoma cells. EMBO J. 1983;2(12):2355-61. 
30. Adewumi O, Aflatoonian B, Ahrlund-Richter L, Amit M, Andrews PW Beighton $\mathrm{G}$, et al. Characterization of human embryonic stem cell lines by the International Stem Cell Initiative. Nat Biotechnol. 2007;25(7):803-16.

31. Khoo CP, Micklem K, Watt SM. A comparison of methods for quantifying angiogenesis in the Matrigel assay in vitro. Tissue Eng Part C Methods. 2011;17(9):895-906.

32. Krebsbach PH, Kuznetsov SA, Satomura K, et al. Bone formation in vivo: comparison of osteogenesis by transplanted mouse and human marrow stromal fibroblasts. Transplantation. 1997;63(8):1059-69.

33. Yang SE, Ha CW, Jung M, et al. Mesenchymal stem/progenitor cells developed in cultures from UC blood. Cytotherapy. 2004;6(5):476-86.

34. Zhang $X$, Hirai M, Cantero S, et al. Isolation and characterization of mesenchymal stem cells from human umbilical cord blood: reevaluation of critical factors for successful isolation and high ability to proliferate and differentiate to chondrocytes as compared to mesenchymal stem cells from bone marrow and adipose tissue. J Cell Biochem. 2011;112(4):1206-18.

35. Robinson SN, Ng J, Niu T, et al. Superior ex vivo cord blood expansion following co-culture with bone marrow-derived mesenchymal stem cells. Bone Marrow Transplant. 2006;37(4):359-66.

36. Bari S, Seah KK, Poon Z, et al. Expansion and homing of umbilical cord blood hematopoietic stem and progenitor cells for clinical transplantation. Biol Blood Marrow Transplant. 2015:21(6):1008-19.

37. Crisan $M$, Yap S, Casteilla $L$, et al. A perivascular origin for mesenchymal stem cells in multiple human organs. Cell Stem Cell. 2008;3(3):301-13.

38. Thomson JA, Itskovitz-Eldor J, Shapiro SS, et al. Embryonic stem cell lines derived from human blastocysts. Science. 1998;282(5391):1145-7.

39. Zuba-Surma EK, Klich I, Greco N, et al. Optimization of isolation and further characterization of umbilical-cord-blood-derived very small embryonic/ epiblast-like stem cells (VSELs). Eur J Haematol. 2010;84(1):34-46.

40. Danova-Alt R, Heider A, Egger D, et al. Very small embryonic-like stem cells purified from umbilical cord blood lack stem cell characteristics. PLoS One. 2012;7(4):e34899. doi:10.1371/journal.pone.0034899.

41. Croft AP, Przyborski SA. Formation of neurons by non-neural adult stem cells: potential mechanism implicates an artifact of growth in culture. Stem Cells. 2006;24(8):1841-51.

42. Pittenger MF, Martin BJ. Mesenchymal stem cells and their potential as cardiac therapeutics. Circ Res. 2004:95(1):9-20.

43. Munoz JR, Stoutenger BR, Robinson AP, et al. Human stem/progenitor cells from bone marrow promote neurogenesis of endogenous neural stem cells in the hippocampus of mice. Proc Natl Acad Sci U S A. 2005;102(50):18171-6.

44. Viswanathan SR, Powers JT, Einhorn W, et al. Lin28 promotes transformation and is associated with advanced human malignancies. Nat Genet. 2009;41(7):843-8.

45. Chen AX, Yu KD, Fan L, et al. Germline genetic variants disturbing the Let 7/LIN28 double-negative feedback loop alter breast cancer susceptibility. PLoS Genet. 2011;7(9):e1002259. doi:10.1371/journal.pgen.1002259.

46. Takahashi K, Tanabe K Ohnuki M, et al. Induction of pluripotent stem cells from adult human fibroblasts by defined factors. Cell. 2007;131(5):861-72.

47. Yu J, Vodyanik MA, Smuga-Otto K, et al. Induced pluripotent stem cell lines derived from human somatic cells. Science. 2007;318(5858):1917-20.

48. Pera MF. Stem cells: the dark side of induced pluripotency. Nature. 2011;471(7336):46-7.

49. Apostolou E, Hochedlinger K. Stem cells: iPS cells under attack. Nature. 2011:474(7350):165-6.

50. Brand A, Rebulla P, Engelfriet $C P$, et al. Cord blood banking. Vox Sang 2008;95(4):335-48

51. McGuckin CP, Forraz N. Potential for access to embryonic-like cells from human umbilical cord blood. Cell Prolif. 2008:41 Suppl 1:31-40.

\section{Submit your next manuscript to BioMed Central} and we will help you at every step:

- We accept pre-submission inquiries

- Our selector tool helps you to find the most relevant journal

- We provide round the clock customer support

- Convenient online submission

- Thorough peer review

- Inclusion in PubMed and all major indexing services

- Maximum visibility for your research

Submit your manuscript at www.biomedcentral.com/submit
Biomed Central 